\title{
Mammary and extramammary Paget's disease
}

Lauro Lourival Lopes Filho ${ }^{1}$

Lauro Rodolpho Soares Lopes ${ }^{1}$

Alexandre Osores Michalany ${ }^{3,4}$

\author{
Ione Maria Ribeiro Soares Lopes ${ }^{1}$ \\ Milvia M. S. S. Enokihara² \\ Nobuo Matsunaga ${ }^{5}$
}

\begin{abstract}
Paget's disease, described by Sir James Paget in 1874, is classified as mammary and extramammary. The mammary type is rare and often associated with intraductal cancer (93-100\% of cases). It is more prevalent in postmenopausal women and it appears as an eczematoid, erythematous, moist or crusted lesion, with or without fine scaling, infiltration and inversion of the nipple. It must be distinguished from erosive adenomatosis of the nipple, cutaneous extension of breast carcinoma, psoriasis, atopic dermatitis, contact dermatitis, chronic eczema, lactiferous ducts ectasia, Bowen's disease, basal cell carcinoma, melanoma and intraductal papilloma. Diagnosis is histological and prognosis and treatment depend on the type of underlying breast cancer. Extramammary Paget's disease is considered an adenocarcinoma originating from the skin or skin appendages in areas with apocrine glands. The primary location is the vulvar area, followed by the perianal region, scrotum, penis and axillae. It starts as an erythematous plaque of indolent growth, with well-defined edges, fine scaling, excoriations, exulcerations and lichenification. In most cases it is not associated with cancer, although there are publications linking it to tumors of the vulva, vagina, cervix and corpus uteri, bladder, ovary, gallbladder, liver, breast, colon and rectum. Differential diagnoses are candidiasis, psoriasis and chronic lichen simplex. Histopathology confirms the diagnosis. Before treatment begins, associated malignancies should be investigated. Surgical excision and micrographic surgery are the best treatment options, although recurrences are frequent.
\end{abstract}

Keywords: Breast neoplasms; Paget Disease, extramammary; Paget's disease, mammary

\section{HISTORY}

Sir James Paget, a British surgeon and physiologist, first described Paget's disease in $1874 .{ }^{1}$ At the time, he portrayed a disease that presented itching, excoriation, erythema and liquid nipple discharge and that was associated with underlying cancer in the mammary gland. Butlin detailed the peculiar histopathology two years later.

\section{CLASSIFICATION}

\section{Mammary Paget's disease \\ Extramammary Paget's disease \\ MAMMARY PAGET'S DISEASE (MPD)}

\section{EPIDEMIOLOGY}

This is a rare disease that corresponds to $1-4.3 \%$ of all breast cancers and is frequently associated with intraductal, in situ or invasive neoplasms. It is more prevalent in postmenopausal women, usually after the sixth decade of life, but it has also been reported in adolescent and elderly patients. ${ }^{2,3,4}$ It may affect male patients, albeit more rarely.

\section{CLINICAL PRESENTATION}

The disease has an insidious onset, evolving over months or years for the most part unilaterally, although rare bilateral cases have been reported. ${ }^{5}$ It starts in the nipple, then extends to the areola, and in more advanced cases to the surrounding skin, as eczematoid, erythematous, thickened, moist or crusted lesions, with irregular borders, with or without fine scaling, induration, infiltration, secretion, bleeding, ulceration and nipple invagination (Figure 1). ${ }^{6}$ In

Received on 02.10.2013.

Approved by the Advisory Board and accepted for publication on 16.12.2014

Work performed at Hospital Getúlio Vargas - Dermatology and Gynecology Clinics (UFPI), Universidade Federal de São Paulo - Dermatopathology Service (UNIFESP), Universidade de Santo Amaro - Dermatology Service (UNISA), Hospital do Servidor Público Municipal de São Paulo - São Paulo - Dermatology Service and Faculdade de Medicina do ABC - Dermatology Service

Conflict of interest: None

Financial Support: None

Universidade Federal do Piauí (UFPI) - Teresina (PI), Brazil.

Universidade Federal de São Paulo (UNIFESP) - São Paulo (SP), Brazil

Universidade de Santo Amaro (UNISA) - Santo Amaro (SP), Brazil.

Hospital do Servidor Público Municipal de São Paulo- São Paulo (SP), Brazil.

Faculdade de Medicina do ABC (FMABC) - Santo André (SP), Brazil. 
some cases the aspect is psoriasiform, in others it simulates inflammatory and eczematous conditions; hyperpigmented lesions similar to superficial spreading melanoma have been reported. It is often asymptomatic at the beginning, but during evolution pruri-
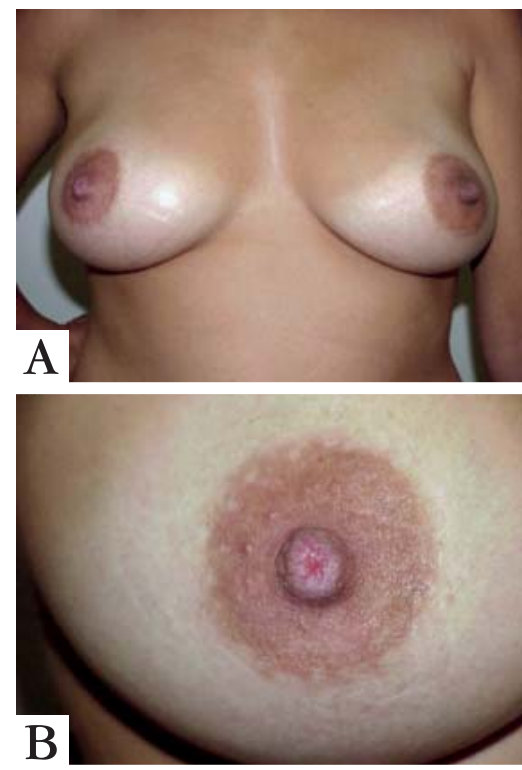

FIGURE 1

A: Initial mammary Paget's diseas. Observe u n i l a t e r a 1 involvement on right nipple. B - D e t a i l e d depiction on the previous figure (Courtesy from Dr. Samuel Freire da Silva) C$\mathrm{M}$ a $\mathrm{m} \mathrm{m}$ a $\mathrm{r} \mathrm{y}$ Paget's disease also affecting the areola

tus, burning sensation and pain can be present. In very advanced stages, serous and/or bloody papillary discharge, as well as destruction of the papillary-areolar complex may be observed. At the time of diagnosis, lesions' diameters vary from 0.3 to $15 \mathrm{~cm}$. The disease can also occur in ectopic breasts and accessory nipples.?

Between $93-100 \%$ of MPD cases are associated with underlying breast cancer, usually central and multifocal tumors, mainly located near the areola. In nearly half the affected patients there is a palpable tumor mass in the breast, characterized as an invasive tumor. When this mass is not clinically evident, intraductal cancers are in situ. ${ }^{8,9}$ It may affect male patients and the clinical characteristics are similar to those occurring in women. ${ }^{10,11}$

\section{INVESTIGATION OF ASSOCIATED BREAST CANCER}

Confronted with a diagnosis of MPD, it is essential to investigate mammary gland neoplasm. This type of cancer may be in situ or invasive, but it is almost always present. A careful clinical examination and imaging exams assessment are necessary for diagnostic conclusion.

Mammograms can detect masses or calcifications that represent invasive or in situ ductal carcinoma, especially when these lesions are palpable. However, a negative exam does not exclude the presence of tumors. Some studies report rates of mammographically occult neoplasms ranging from 15 to $65 \%{ }^{12,13}$

Ultrasound is particularly useful in cases with negative mammograms. However, findings are nonspecific, showing only parenchymal heterogeneity, hypoechoic areas, discrete masses, cutaneous thickening and ductal dilation. Magnetic resonance is highly sensitive for the diagnosis of breast neoplasms, especially if mammography and ultrasound are normal. It may demonstrate thickening of the papillary-areolar complex, increase in nipple size, detection of in situ ductal lesions and invasive tumors, even in clinically unsuspected cases. ${ }^{14}$

\section{HISTOPATHOLOGY}

MPD is histopathologically characterized by epidermal Paget cells, which are malignant glandular epithelial cells with abundant and clear cytoplasm, usually containing mucin, and pleomorphic and hyperchromatic nucleus. These cells appear organized in groups, with nest-like patterns or gland-like structures, and are preferably located in the epidermal basal layer. The number of cells varies from a few to large quantities; even completely replacing the epidermal cells. Invasion of adnexal structures can occur. Ortho-and parakeratosis may be present. The dermis displays reactive characteristics, with telangiectasia, chronic inflammation and ulceration in more advanced cases.

Figure 2 shows histopathological findings of epidermal Paget's disease and in situ dermal ductal carcinoma in the same biopsy sample.

Immunohistochemistry is very useful in MPD for differential diagnoses and histogenesis. Overexpression of the low molecular weight cytokeratins, notably CK7, and lack of expression of high molecular weight cytokeratins, such as CK10, CK14 and CK20 are observed. ${ }^{15,16}$ Paget cells have the same immunohistochemical staining pattern as the underlying breast cancer cells. Furthermore, they also express carcinoembryonic antigen, epithelial membrane antigen, and some mucins. Since breast cancers associated to MPD are poorly differentiated, estrogen 

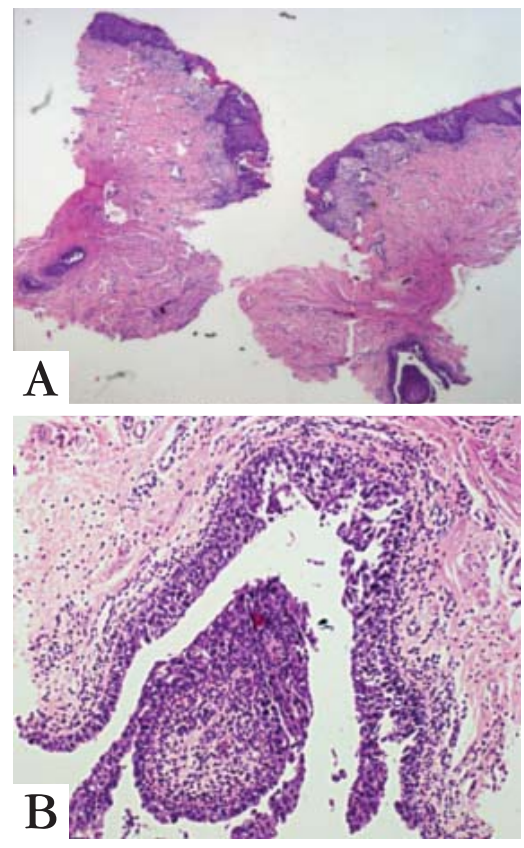

FIGURE 2:

$\mathrm{M}$ a $\mathrm{m} \mathrm{m}$ a $\mathrm{r} \mathrm{y}$ Paget's disease in the nipple associated, in the same biopsy, with mammary duct in situ carcinoma (HE, 40x)

and progesterone antigens are frequently negative. Mori et al found overexpression of oncogenic ras and p21 in mammary and extramammary diseases. ${ }^{17}$ Paget cells express p53, p21, Ki-67, cyclin D1, androgen receptors and Her-2 oncoprotein. ${ }^{18-22}$ Recent studies have shown that the expression of NY-BR-1, a breast differentiation antigen, may have a role in MPD's pathogenesis. ${ }^{23}$

\section{HISTOGENESIS}

The histogenesis of MPD is controversial. There are two main hypotheses that try to explain it and a third that would represent the combination of them:

- Epidermotropic Theory

- Degeneration of Pre-Existing Cells Theory

Epidermotropic theory states that Paget cells would be cells from the generally present underlying intraductal cancer that migrated through the basement membrane to the nipple. Furthermore, recent studies have shown that, in most cases, there is considerable similarity in immunohistochemical staining between MPD and the associated intraductal cancer. ${ }^{24}$ In support of this theory, authors detected an overexpression of Her-2 protein in Paget cells suggesting that keratinocytes would synthesize heregulin-alpha, a mobility factor that would attract Paget cells to the nipple. ${ }^{25}$

The second theory, the degeneration of preexisting cells, considers that Paget cells are keratinocytes that have undergone malignant transformation and that the disease is an in situ carcinoma regardless of the underlying intraductal carcinoma. ${ }^{26}$ Proponents of this theory argue that ultrastructural studies have found microvilli and desmosomes between Paget cells and local keratinocytes. ${ }^{27}$ Further studies are needed to reach a definitive conclusion.

A third theory attempts to combine the two previous ones, suggesting that Paget cells can originate in both ways already mentioned, depending on local circumstances. ${ }^{28}$ The frequent expression of breast differentiation antigen NY-BR-1 was demonstrated in a recent study in MPD and EMPD, suggesting that it may be used as a marker for these diseases. ${ }^{29}$

\section{DIAGNOSIS}

All unilateral persistent inflammatory lesions, located in the nipple and/or areola should prompt an investigation for MPD. ${ }^{30}$

Diagnosis is clinical and histopathological. Biopsy can be performed by "shaving", "punch" or incisional techniques, the latter being the most appropriate one. It is essential that the sample contains part of the lactiferous duct and if the areola is affected, it also needs to be represented in the sample to confirm the diagnosis. Often histological exams are inconclusive and more biopsies, or even surgical removal of the entire nipple may be required. The main histological characteristic is the presence of Paget cells, which are arranged in solid groups. On occasion, they form glandular arrangements outlining the basal epidermis and exhibit migration to the granular layer, similarly to melanocytes. Immunohistochemical methods, such as CK7, Her-2 oncoprotein and carcinoembryonic antigen, in addition to histochemical methods for acid mucin (colloidal iron, Alcian Blue and Mayer's mucicarmine) can be used for diagnostic conclusion, although negative results do not exclude the possibility. CK7 and Her-2 are considered specific and sensitive MPD markers. ${ }^{31}$ In 2013, Crignis et al made a dermoscopic study of polarized light in a classic case of MPD (non-pigmented) and found the presence of "chrysalis-like" structures, a feature described lately in the literature but not yet reported in MPD cases. ${ }^{32}$ One study was recently published on the use of confocal microscopy in 10 patients with MPD and EMPD, with satisfactory results. ${ }^{33}$

\section{DIFFERENTIAL DIAGNOSES}

Erosive adenomatosis of the nipple can simulate MPD when the latter is circumscribed to the nipple. The chronic evolution and histopathological results make the diagnosis. Cutaneous extension of a mammary carcinoma is rare and should be suspected in case of nipple retraction or adherence. Once more, histopathological results set the diagnosis. Differential diagnoses should also be made with 
inflammatory diseases, including psoriasis, atopic dermatitis, chronic contact dermatitis and lactiferous duct ectasia. Bowen's disease, superficial and pagetoid basal cell carcinoma, superficial spreading melanoma (if there is hyperpigmentation) and benign intraductal papilloma, should also be considered. ${ }^{34}$ Because of the clinical resemblance between MPD and these diseases, often the diagnosis is not made or is delayed, with consequent worsening of the prognosis.

\section{PROGNOSIS}

Some factors indicate an unfavorable prognosis, among them: the presence of a palpable breast tumor, enlarged lymph nodes, histological type of breast cancer and patients younger than 60 years. When there is a palpable breast mass, almost always the carcinoma is invasive and associated with high rates of axillary lymph node metastases. Lymph node involvement is correlated with median survival rates, reaching 75$95 \%$ when negative and 20 to $25 \%$ when positive. In another study, the mean 10-year survival rate was estimated at $47 \%$ in cases with positive lymph nodes and $93 \%$ in those with negative lymph nodes. ${ }^{35}$ When the disease occurs in males, the prognosis is poor, with an average 5 -year survival rate of $20-30 \%$.

\section{TREATMENT}

Treatment depends on clinical, radiological and histopathological features of the associated breast cancer, and on metastatic lymph node involvement. Mastectomy with or without axillary lymph node dissection, even in the absence of other malignancy signs, is considered the best therapy for MPD.

Recently, with the increase in early diagnosis in breast cancer, multiple prospective randomized trials were conducted showing that more conservative surgical treatments are possible alternatives, if the disease is limited to the central segment of the breast. Among those therapies are: partial or total exclusive nipple excision, central segmentectomy alone or followed by radiation therapy, and radiotherapy without surgical resection. ${ }^{34,35,36,37}$ Since these are not yet established therapies, if they are adopted patients should be followed closely, even with regular mammograms.

Complementary treatments depend on the final tumor staging and lymph node metastases.

\section{EXTRAMAMMARY PAGET'S DISEASE HISTORY}

In 1889, Radcliffe Crocker first described extramammary Paget's disease (EMPD) in a patient with urinary bladder carcinoma, who presented an eczematous lesion on the penis and scrotum. Darier and Coulillaud described the perianal location of EMPD in 1893.

\section{HISTOGENESIS}

It is considered a rare adenocarcinoma that originates from the skin or skin appendages in areas with apocrine glands. It is believed that, the disease originates from pluripotent stem cells and it has clinical and histological features similar to MPD.

\section{EPIDEMIOLOGY}

The exact incidence is not known, although it is more common in Caucasian postmenopausal women. In a study with 1,439 patients, the authors reported 965 women and 474 men, with mean age of 72 years (range 63-79). The majority was Caucasian..$^{38}$

\section{CLASSIFICATION}

EMPD classification is based on the presence or absence of associated malignancies:

\section{Primary or intraepithelial \\ 2. Secondary}

The secondary type is associated with underlying carcinoma or distant tumors. ${ }^{38,39}$

\section{CLINICAL PRESENTATION}

The main anatomical location is the vulva, with $65 \%$ of cases, followed by the perianal region (which is more frequent in males), scrotum, penis and axilla (Figures 3, 4 and 5). ${ }^{39}$ In most cases, it is an intraepithelial lesion not associated with any underlying or distant cancer. There are, however, several publications linking vulvar EMPD with cancer of the vulva, vagina, cervix and uterus, bladder, ovary, gallbladder, liver, breast, colon and rectum, in rates that vary from $4-20 \%{ }^{40,41}$ The anorectal location is mostly associated with stomach, breast and colorectal carcinomas.

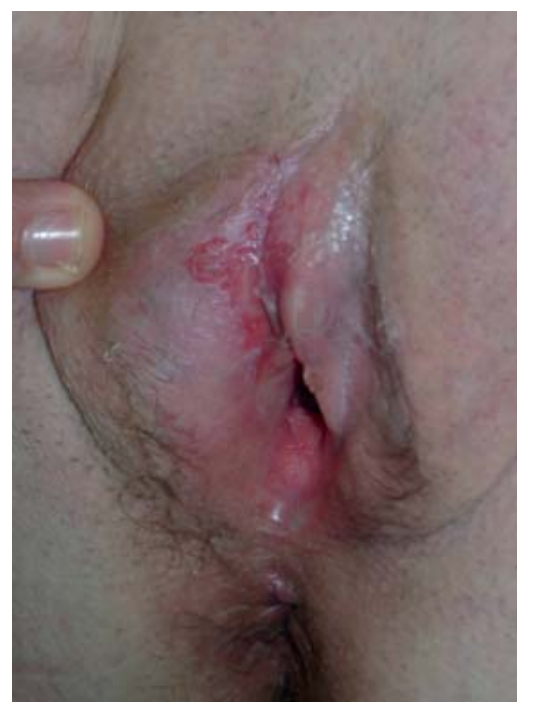

FIGURE 3 :

Vulvar Paget's disease 


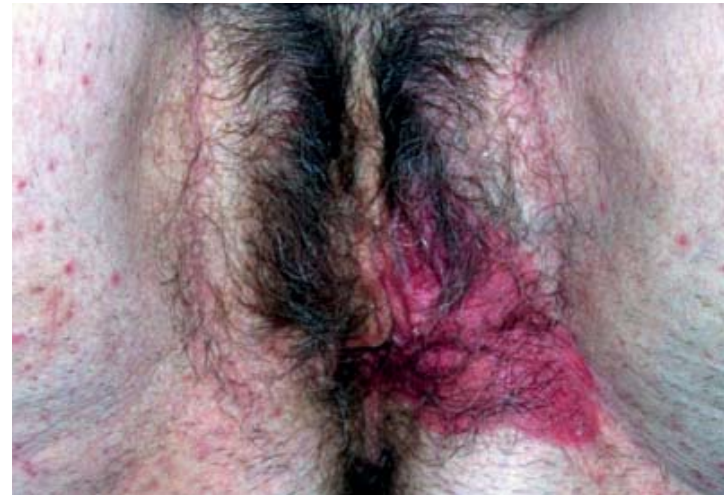

FIGURE 4: Paget's disease affecting vulva, perineal region and part of the inguinocrural sulcus
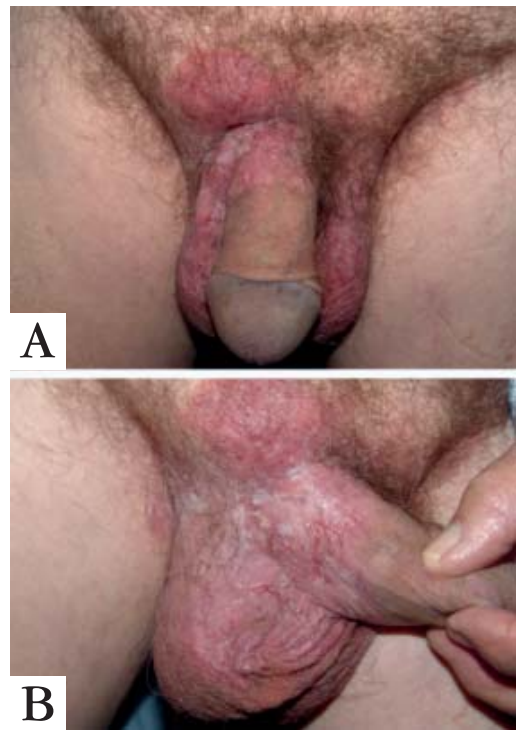

FIGURE5A AND5B:

Extramammary

Paget's disease in male genitals

Primary EMPD can evolve to invasive adenocarcinoma, with inherent metastatic potential to regional lymph nodes and distant organs. ${ }^{38}$

The disease appears as an erythematous plaque, with indolent growth, very well defined borders and the presence of fine scales. It may be asymptomatic or present various degrees of burning sensation and pruritus, which may even lead to the appearance of excoriations, exulcerations and lichenification. In the later stages, it may become infiltrated. This disease is usually multifocal with sub-clinical extension, which sometimes hinders the establishment of precise limits with normal skin.

\section{DIAGNOSIS AND DIFFERENTIAL DIAGNOSES}

Diagnosis is clinical and must be confirmed by histopathology. Confocal microscopy was useful in the diagnosis of a few cases, as recently published. ${ }^{42}$ Histopathology reveals the presence of Paget cells in the epidermis, as seen in Figures 6A and 6B. When histochemical reactions for acid mucin, such as Alcian Blue, colloidal iron and mucicarmine Mayer are used, the presence of this substance is detected in the cytoplasm of neoplastic cells. Immunohistochemical examination is very important to the differential diagnoses with Bowen's disease, amelanotic superficial spreading melanoma and to determine whether it is a primary or secondary disease..$^{43}$ Cutaneous melanoma expresses Melan A, S100 and HMB45 but not the other antibodies, while Bowen's disease expresses AE1AE3, p63 and eventually CK7 (Figure 7). The immunohistochemical marker GCDFP-15 (or BRST2) is expressed in $50 \%$ of cases of primary EMPD and it is negative in secondary types. ${ }^{44}$ Figure 8 shows focal positivity for this marker in EMPD.

Depending on the morphological aspects found, especially absence of glandular arrangement patterns and only Pagetoid migration through epidermic layers besides lack of melanin pigment in amelanotic melanoma, a more detailed investigation of the neoplasm is necessary to exclude other differential diagnoses (Table 1). Langerhans cell histiocytosis,

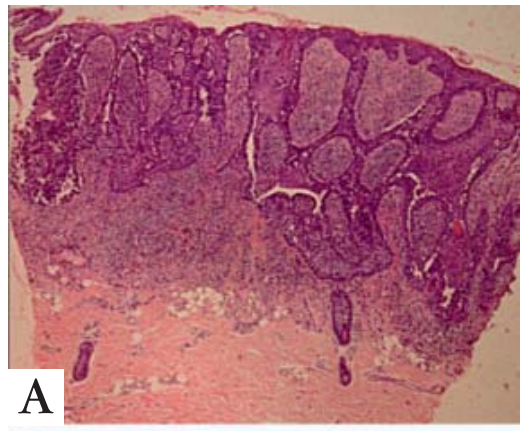

FIGURE 6:A:

Epidermis showing intense thickening due to the proliferation of atypical

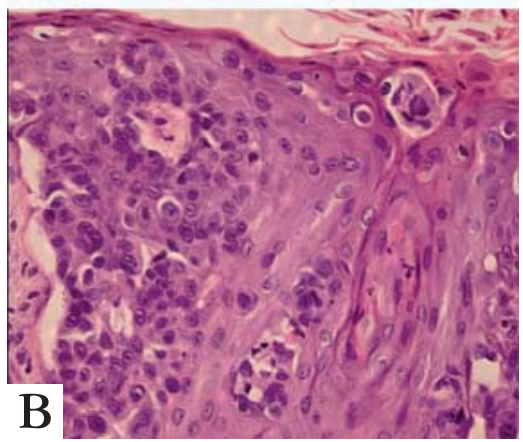
cells in Paget's disease (HE, 40x). B: $\mathrm{P}$ a g e $\mathrm{t}$ o i d migration of atypical epithelial cells, near the granular layer, some with a clear cytoplasm (HE, 400x) 


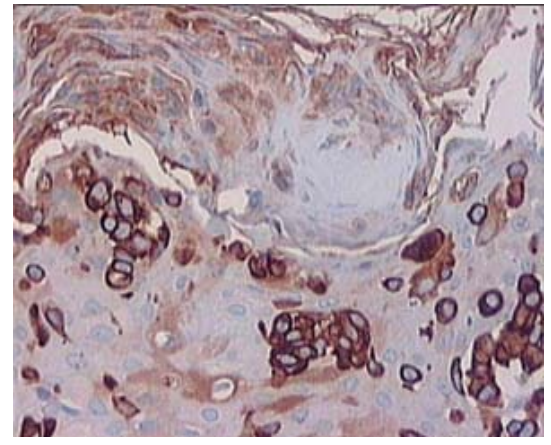

FIGURE 7: CK7 immunoreactivity in several neoplastic cells (400x)

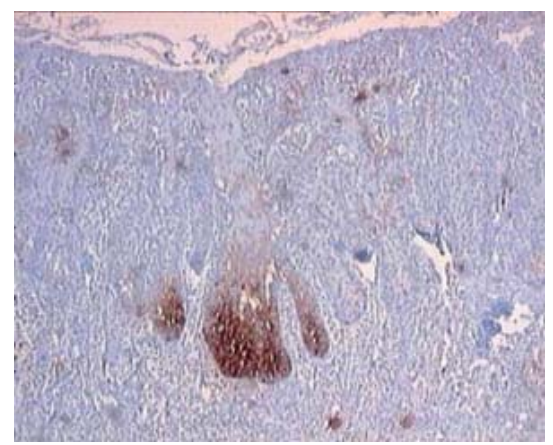

FIGURE 8: BRST2 or GCDFP-15 $\mathrm{m}$ a $\mathrm{r} \mathrm{k}$ e $\mathrm{r}$ (gross cystic disease fluid protein-15) with focal positivity in E M P D (400X)

\section{TREATMENT}

Before any therapeutic measure is taken, a thorough and careful investigation to detect the presence or absence of associated malignancy is essential, especially in cases with perianal lesions. Surgical excision with ample margins and micrographic surgery are the best treatment options, nonetheless relapses are frequent due to the sub-clinical extent of the disease. Studies using photodynamic therapy have been published, however achieving solely palliative results. ${ }^{46}$ Imiquimod cream at 5\% concentration ${ }^{29}, 5 \% 5$-fluorouracil cream, $\mathrm{CO}_{2}$ laser and the association of two or more therapeutic approaches may also be used, with variable results. ${ }^{47}$ Since relapses are very common with any of the available therapeutic options, close monitoring for long periods is mandatory. $]$

TABLE 1: Histological and immunohistochemical differential diagnoses of mammary and extramammary Paget's disease

\begin{tabular}{lcccc}
\hline METHODS & Primary extramammary & $\begin{array}{l}\text { Secondary extramammary } \\
\text { Paget's disease }\end{array}$ & $\begin{array}{l}\text { Bowen's disease } \\
\text { melanoma }\end{array}$ & Superficial spreading \\
\hline PAS diastase resistant & + & + & - & - \\
Mayer's mucicarmine & + & + & - & - \\
Alcian Blue & + & + & - & - \\
Colloidal iron & + & + & + & - \\
Fontana Masson & - & + & + or - \\
Pancytokeratin (AE1AE3) & + & + & - & - \\
CK7 & + & + & - & - \\
EMA & + & + & - & - \\
CEA & + & - & + \\
GCDFP-15 & + & - & - \\
Melan-A & - & - & - \\
P63 & - & - & - \\
S100 protein & - & - & + \\
HMB45 & - & & + \\
\hline
\end{tabular}

which can be morphologically similar to Paget's disease, is another possible differential diagnosis. In this case there will be immunoreactivity of a specific marker for Langerhans cells - CD1a, while Paget's disease markers will be negative. ${ }^{45}$

Cutaneous candidiasis, chronic lichen simplex and psoriasis should also be excluded through direct mycological examination, mycological culture and histopathology.

\section{ACKNOWLEDGMENT}

We thank Dr. Andrelou Fralete Ayres Vallarelli for his invaluable assistance in the preparation and submission of photographs. We also thank Dr. Samuel Freire da Silva for allowing the use of photographs from his personal collection in this work. 


\section{REFERENCES}

1. Paget J. On the disease of the mammary areola preceding cancer of the mammary gland. St Bartholomew,s Hosp Rep. 1874;10:87-9.

2. Kanitakis J. Mammary e extramammary Paget's disease. J Eur Acad Dermatol Venereol. 2007;21:581-90.

3. Martin VG, Pellettiere EV, Gress D, Miller AW. Paget's disease in an adolescent arising in a supernumerary nipple. J Cutan Pathol. 1994;21:283-6.

4. Ascensõ AC, Marques MS, Capitão-Mor M. Paget's disease of the nipple. Clinical and pathological review of 109 female patients. Dermatologica. 1985;170:170-9.

5. Franceschini G, Masetti R, D'Ugo D, Palumbo F, D'Alba P, Mulè A,et al. Synchronous bilateral Paget's disease of the nipple associated with bilateral breast carcinoma. Breast J. 2005;11:355-6.

6. Karakas C. Paget's disease of the breast. J Carcinog. 2011;10:31.

7. Kao GF, Graham JH, Helwig EB. Paget's disease of the ectopic breast with an underlying intraductal carcinoma: report of a case. J Cutan Pathol. 1986;13:59-66.

8. Yim JH, Wick MR, Philpott GW, Norton JA, Doherty GM. Underlying pathology in mammary Paget's disease. Ann Surg Oncol. 1997;4:287-92.

9. Kothari AS, Beechey-Newman N, Hamed H, Fentiman IS, D'Arrigo C, Hanby AM,et al. Paget's disease of the nipple: a multifocal manifestation of higher-risk disease. Cancer. 2002;95:1-7.

10. Ho TC, St Jacques M, Schopflocher P. Pigmented Paget's disease of the male breast. J Am Acad Dermatol. 1990;23:338-41.

11. Deasai DC, Brennan RJ, Carp NZ. Paget's disease on the male breast. Am Surg.1996;62:1068-72.

12. Günhan-Bilgen I, Oktay A. Paget's disease of the breast: clinical, mammographic, sonographic and pathologic findings in 52 cases. Eur J Radiol. 2006;60:256-63

13. Morrogh M, Morris EA, Liberman L, Van Zee K, Cody HS 3rd, King TA. MRI identifies otherwise occult disease in select patients with Paget's disease of the nipple. J Am Coll Surg. 2008;206:316-21.

14. Frei KA, Bonel HM, Pelte MF, Hylton NM, Kinkel K. Paget disease of the breast: findings at magnetic resonance imaging and histopathologic correlation. Invest Radiol. 2005;40:363-7.

15. Yao DX, Hoda SA, Chiu A, Ying L, Rosen PP. Intraepidermal cytokeratin 7 immunoreactive cells in the non-neoplastic nipple may represent interepithelialextension of lactiferous duct cells. Histopathology. 2002;40:230-6.

16. Smith KJ, Tuur S, Corvette D, Lupton GP, Skelton HG. Cytokeratin 7 staining in mammary and extramammary Paget's disease. Mod Pathol. 1997;10:1069-74.

17. Mori O, Hachisuka H, Nakano S, Sasai Y, Shiku H. Expression for ras p21 in mammary and extramammary Paget's disease. Arch Pathol Lab Med. 1990;114:858-61.

18. Kanitakis J, Thivolet J, Claudy A.p53 protein expression in mammary and extramammary Paget's disease. Anticancer Res. 1993;13:2429-33.

19. Ellis PE, Fong LF, Rolfe KJ, Crow JC, Reid WM, Davidson T,et al. The role of p53 and Ki-67 in Paget's disease of the vulva and the breast. Gynecol Oncol. 2002;86:150-6.

20. Fu W, Lobocki CA, Silberberg BK, Chelladurai M, Young SC. Molecular markers in Paget disease of the breast. J Surg Oncol. 2001;77:171-8.

21. Liegl B, Horn LC, Moinfar F. Androgen receptors are frequently expressed in mammary and extramammary Paget's disease. Mod Pathol. 2005;18:1283-8.

22. Sek P, Zawrocki A, Biernat W, Piekarski JH. HER2 molecular subtype is dominant subtype of mammary Paget's cells. An immunohistochemical study. An immunohistochemical study. Histopathology. 2010;57:564-71.

23. Giger 0 , Caduff R, O'Meara A, Diener PA, Knuth A, Jäger D,et al. Frequent expression of the breast differentiation antigen NY-BR-1 in mammary and extramammary Paget's disease. Pathol Int. 2010;60:726-34.

24. Cohen C, Guarner J, DeRose PB. Mammary Paget's disease and associated carcinoma. An immunohistochemical study. Arch Pathol Lab Med. 1993;117:291-4.

25. Schelfhout VR, Coene ED, Delaey B, Thys S, Page DL, De Potter CR. Pathogenesis of Paget's disease: epidermal heregulin-alpha, motility factor and the HER receptor family. J Natl Cancer Inst. 2000;92:622-8.

26. Lagios MD, Westdahl PR, Rose MR, Concannon S. Paget's disease of the nipple. Alternative management in cases without or with minimal extent of underlying breast carcinoma. Cancer. 1984;54:545-51.

27. Jahn H1, Osther PJ, Nielsen EH, Rasmussen G, Andersen J. An electron microscopic study of clinical Paget's disease of the nipple. APMIS. 1995 Sep;103:628-34.
28. Lloyd J, Flanagan AM. Mammary and extramammary Paget's disease. J Clin Pathol. 2000;53:742-9.

29. Cohen PR, Schulze KE, Tschen JA, Hetherington GW, Nelson BR. Treatment of extramammary Paget disease with topical imiquimod cream: case report and literature review. South Med J. 2006;99:396-402.

30. Brown HM, Wilkinson EJ. Uroplakin-III to distinguish vulvar Paget disease secondary to urothelial carcinoma. Hum Pathol. 2002;33:545-8.

31. Keatings L, Sinclair J, Wright C, Corbett IP, Watchorn C, Hennessy C, et al. C-erbB2 oncoprotein expression in mammary and extramammary Paget's disease: an immunohistochemicalstudy. Histopathology. 1990;17:243-7.

32. Crignis GS, Abreu Ld, Buçard AM, Barcaui CB. Polarized dermoscopy of mammary Paget disease. An Bras Dermatol. 2013;88:290-2.

33. Kawase K, Dimaio DJ, Tucker SL, Buchholz TA, Ross MI, Feig BW,et al. Paget's disease of the breast: there is a role for breast-conserving therapy. Ann Surg Oncol. 2005; $12: 391-7$

34. Gabbi TV, Valente NY, Castro LG. Pigmented Paget's disease of the nipple mimicking cutaneous melanoma: importance of the immunohistochemical profile to differentiate between these diseases. An Bras Dermatol. 2006;81:457-60.

35. Dixon AR, Galea MH, Ellis I0, Elston CW, Blamey RW. Paget's disease of the nipple. Br J Surg. 1991;78:722-3.

36. Bulens P, Vanuytsel L, Rijnders A, van der Schueren E. Breast conserving treatment of Paget's disease. Radiother Oncol. 1990;17:305-9.

37. Stockdale AD, Brierley JD, White WF, Folkes A, Rostom AY. Radiotherapy for Paget's disease of the nipple: a conservative alternative. Lancet. 1989;2:664-6.

38. Karam A, Dorigo 0. Treatment outcomes in a large cohort of patients with invasive Extramammary Paget's disease. Gynecol Oncol. 2012;125:346-51.

39. Fanning J, Lambert HC, Hale TM, Morris PC, Schuerch C. Paget's disease of the vulva: prevalence of associated vulvar adenocarcinoma, invasive Paget's disease, and recurrence after surgical excision. Am J Obstet Gynecol. 1999;180:24-7.

40. Nakano S, Narita R, Tabaru A, Ogami Y, Otsuki M. Bile duct cancer associated with extramammary Paget's disease. Am J Gastroenterol. 1995;90:507-8.

41. Popiolek DA, Hajdu SI, Gal D. Synchronous Paget's disease of the vulva and breast. Gynecol Oncol. 1998;71:137-40.

42. Guitera P, Scolyer RA, Gill M, Akita H, Arima M, Yokoyama Y,et al. Reflectance confocal microscopy for diagnosis of mammary and extramammary Paget's disease. J Eur Acad Dermatol Venereol. 2013;27:e24-9.

43. Liegl B, Leibl S, Gogg-Kamerer M, Tessaro B, Horn LC, Moinfar F. Mammary and extramammary Paget's disease: an immunohistochemical study of 83 cases. Histopathology. 2007;50:439-47.

44. McKee PH, Hertogs KT. Endocervical adenocarcinoma and vulvar Paget's disease: a significant association. Br J Dermatol. 1980;103:443-8.

45. Ansari B, Purdie CA, Brown DC. Adult Langerhans cell histiocytosis mimicking Paget's disease of the nipple. Breast J. 2005;11:281-2.

46. Nardelli AA, Stafinski T, Menon D. Effectiveness of photodynamic therapy for mammary and extra-mammary Paget's disease: a state of the science review. BMC Dermatol. 2011;11:13.

47. Wilkinson EJ, Brown HM. Vulvar Paget disease of urothelial origin: a report of three cases and a proposed classification of vulvar Paget disease. Hum Pathol. 2002;33:549-54.

MAILING ADDRESS:
Lauro Lourival Lopes Filho
Avenida Marechal Castelo Branco, 670 - Apto. 1600
Bairro Ilhotas
64014-058 - Teresina - PI
Brazil
E-mail: lll@ @uol.com.br

How to cite this article: Lopes Filho LL,Lopes IMRS, Lopes LRS, Enokihara MMSS, Michalany AO, Matsunaga N. Mammary and extramammary Paget's disease. An Bras Dermatol. 2015;90(2):225-31. 